\title{
Projetos de vida na Pós-Modernidade: possibilidades e limites aos jovens
}

Life projects in Post-modernity: possibilities and limits to the young

Proyectos de vida en Posmodernidad: posibilidades y límites a los jóvenes

\author{
Heloisa C. Pereira* \\ Márcia Stengel ${ }^{*}$
}

\begin{abstract}
Resumo
Este artigo discute a temática projeto de vida, considerando a dimensão temporal da Pós-Modernidade. Os projetos fazem parte de nossas vidas em todas as etapas, entretanto, na juventude, esse tema se torna mais pertinente por haver uma exigência social de que os jovens definam alguns caminhos em suas vidas. Discutimos o termo projeto e suas abrangências, explicando seus sentidos, concomitante a estudo bibliográfico sobre juventude, com autores-chave como Melucci, Pais e Dayrell. Apresentamos como a Modernidade e a Pós-Modernidade impactam na visão do homem ao projetar-se. Levantamos questóes vivenciadas atualmente pelos jovens, apontando fatores favorecedores e dificultosos da construção dos projetos diante do cenário de mudanças, marcado por incertezas nas quais estão os jovens, cuja transição para a vida adulta não se encontra definida como outrora. Eles precisam criar planos de curto prazo e desenvolver estratégias para enfrentar essa realidade, assim como elaborar respostas para saídas frente ao futuro imprevisível.
\end{abstract}

Palavras-chave: Projeto de vida. Pós-Modernidade. Juventude.

\begin{abstract}
This article discusses the theme of life project, considering the Postmodernity temporal dimension. The projects are part of our lives at every step, however in youth this theme becomes more relevant because there is a social requirement that young people have to define some paths in their lives. We discussed the project and its own term, explaining your senses, concomitant the bibliographical study on youth, with key authors such as Melucci, Pais and Dayrell. We present how Modernity and Post-modernity
\end{abstract}

\footnotetext{
Texto submetido em 28 de agosto de 2015 e aprovado para publicação em 11 de dezembro de 2015.

Mestra titulada pelo Programa de Pós-Graduação em Psicologia da Pontifícia Universidade Católica de Minas Gerais. Endereço: Rodovia Bambuí-Medeiros, Fazenda Varginha, s/n.o , caixa postal 5 - IFMG - Campus Bambuí, Bambuí-MG, Brasil. CEP: 38900-000. Telefone: (37) 3431 4900. E-mail: helosa.pereira@ifmg.edu.br.

* Professora doutora do Programa de Pós-Graduação em Psicologia da Pontifícia Universidade Católica de Minas Gerais. Endereço: Avenida Itaú, 525, $1^{\circ}$ subsolo - Dom Cabral, Belo Horizonte-MG, Brasil. CEP: 30535-012. Telefone: (31) 33194568. E-mail: marciastengel@gmail.com.
} 
impact on man's vision to project. We raised issues experienced by young people, pointing to factors that help or disfavor the construction of the projects, facing the scenario of changes, marked by uncertainties where are teenagers, whose transition to adulthood is not defined as once was. They need to create short-term plans and develop strategies to address this reality, as well as elaborate responses to making exits to unpredictable future.

Keywords: Life project. Post-modernity. Youth.

\section{Resumen}

Este artículo aborda el tema del proyecto de vida, teniendo en cuenta la dimensión temporal de la Posmodernidad. Los proyectos son parte de nuestras vidas en todas las etapas, sin embargo en la juventud este tema se convierte en más relevante porque hay una exigencia social de que los jóvenes definan algunos caminos en sus vidas. Discutimos el término proyecto y su alcance, explicando sus sentidos, concomitante al estudio bibliográfico sobre juventud, con autores clave como Melucci, Pais y Dayrell. Presentamos como la Modernidad y la Posmodernidad impactan en la visión del hombre al proyectarse. Nos planteamos problemas experimentados actualmente por los jóvenes, señalando factores favorecedores y dificultosos de la construcción de proyectos, ante el escenario de cambios, marcado por las incertidumbres en las cuales están los jóvenes, cuya transición hacia la vida adulta no está definida como lo estaba antiguamente. Ellos necesitan crear planes a corto plazo y desarrollar estrategias para hacer frente a esta realidad, así como elaborar respuestas para salidas frente al impredecible futuro.

Palabras clave: Proyecto de vida. Posmodernidad. Juventud.

ste trabalho aborda uma discussão acerca da temática projeto de vida,
considerando a dimensão temporal da Pós-Modernidade. Compreendemos
que os projetos fazem parte de nossas vidas em todas as suas etapas, entretanto, na juventude, esse tema se torna mais pertinente por haver uma exigência social de que os jovens definam alguns caminhos em suas vidas. Por isso, eles são tomados aqui para discutirmos os projetos de vida na Pós-Modernidade.

Inicialmente fizemos um estudo sobre o termo projeto e suas diversas abrangências, procurando explicar os sentidos atribuídos ao conceito. Com base no termo, trouxemos à tona os atravessamentos sofridos por ele em relação à dimensão temporal, explicitando o papel desta diante da visão do homem ao projetar-se. Nesta caminhada, buscamos autores que discutem a construção dos projetos junto a jovens, procurando elucidar pontos significativos para estes diante da proposta de entrada no mundo adulto. 


\section{Compreendendo sobre projetos}

A palavra projeto etimologicamente deriva do latim projectus, designando algo como um jato lançado para frente. Ao nascer, somos lançados para a vida, e o tornar-se pessoa está diretamente relacionado com a capacidade de antecipar ações e planejar o futuro. No campo da semântica, há uma associação da palavra com o termo desenho ou design, que pode ser compreendido como planos, concepção, criação, esboço, desenho (Machado, 2000).

Ao falarmos de projeto, é importante considerá-lo como narrativas biográficas que envolvem passado, presente e futuro. Assim, seu conceito se articula com a dimensão temporal, de forma que passado, presente e futuro inter-relacionam-se na construção do projeto, como nos fala Alves (2013, p. 140): "Daí que os projetos não devem ser analisados apenas na perspectiva futura, mas na relação que esse futuro almejado guarda com o presente vivido e com o passado experimentado".

Projetar é planejar o futuro, não de modo estático ou determinado, mas um esboço que precisa de açôes para implantar-se o projeto e, por isso, exige certa organização que conduza à realização o mais próximo possível das ideias iniciais. Durante a trajetória de um projeto, muitas são as metas e estas são pensadas e repensadas após cada passo, rumo à sua concretização.

Machado (2000) aponta três características fundamentais para o significado da palavra projeto. Exprime, em primeiro lugar, a antecipação de uma ação relacionada com a referência de futuro. Um projeto precisa ser algo que será realizado pelo sujeito sem certeza dos resultados. Ao referir-se a projeto como antecipação, promovem-se as ações para alcançar os objetivos. Dessa forma, não há como pensar em projeto sem aliar-se à perspectiva de futuro, e este se constrói a partir dos projetos, considerando as vivências do passado e o tempo presente.

A segunda característica de projeto relaciona-se com a abertura para o novo; uma ideia determinada, pronta e acabada não pode ser um projeto. Este se abre para novidades, possibilidades, imaginação e com o eminente risco de insucesso. Ao se planejar um projeto, não se pode ter certeza de seu sucesso tampouco de seu fracasso, é preciso aceitar mudanças de rotas e adequar à realidade conforme ela vai se mostrando.

Como terceira característica, Machado (2000, p. 7) refere-se a "uma ação a ser realizada pelo sujeito que projeta, individual ou coletiva". Não se vive dos projetos de outros nem se constrói projetos para outra pessoa. Essa característica aponta para a concepção do projeto como algo pessoal, construído pelo sujeito diante de suas vivências e realidades. Os projetos até podem ser coletivos, mas, nesse caso, os interesses individuais e coletivos precisam estar em sintonia. Para o autor, os projetos coletivos são essenciais, pois estes estimulam ações particulares, 
possibilitando a construção de algo maior, mais significativo. Então, quando falamos de projeto, é importante que o termo apresente as características apontadas por Machado (2000, p. 8): "A antecipação de uma ação em busca de uma meta, em um futuro não determinado, cuja efetivação depende efetivamente dos agentes". Essa antecipação pode ser entendida desde ações bem simples, como planejar a ida a uma padaria, como mais complexas, que envolvam maior mobilidade e mesmo uma alteração no curso de vida do sujeito, como mudar de cidade para estudar.

Boutinet (2002) aponta quatro tipos da antecipação: as antecipações adaptativas, vistas nas figuras de previsão e previdência; as cognitivas, que se apresentam por meios de adivinhaçôes e profecias; as imaginárias, caracterizadas pelas utopias e ficção científica; e, por fim, as antecipações de tipo operatório, que apresentam objetivos e alvos, com vistas à realização de desejos, planos e projetos. Para o autor, esta última é definida como antecipações de tipo racional ou determinista (o alvo, o objetivo e o plano); de tipo volitivo formal (o desejo e o voto); e de tipo vago ou parcialmente determinada (o projeto registrado, a intenção). Geralmente é nas antecipações do tipo operatório que o indivíduo busca realizar seu futuro pessoal.

Considerando essas características trazidas por Boutinet (2002) e Machado (2000), podemos afirmar que é próprio do ser humano fazer projetos, assim como ter a vida como um projeto, ou seja, o traço mais característico da atividade humana é a capacidade de fazer projetos (Machado, 2000). Pertence a nós, como seres humanos, a faculdade para fazer planos, vislumbrar possibilidades e comprometer-se com o futuro; sem os projetos não se vive.

O projeto de vida nos faz pensar em algo original, dizendo de nossa identidade e da imagem que construímos como sujeitos a partir do que planejamos e realizamos. Machado (2000, p. 17) coaduna essa ideia quando afirma: "Ao desenhar o mundo, desenhamo-nos, ou seja, somos o que contextuadamente projetamos". Se os projetos são parte importante na constituição da identidade do sujeito, como nos diz o autor, precisamos ressaltar que eles indicam os valores de quem os planeja.

A juventude é marcada pelas incertezas das mudanças da transição entre a infância e a idade adulta. Paralelo às várias modificações, psíquicas e sociais, que resultam no processo de subjetivação próprio de cada indivíduo, evidenciam-se as ideias para planejar o futuro. $\mathrm{O}$ jovem se vê obrigado a responder as exigências da sociedade ao nível afetivo, cultural e social, a fim de adentrar na vida adulta.

É diante das definições de projeto que podemos considerar que o termo não representa algo fechado, que expressa as açôes dos jovens frente às suas perspectivas 
de futuro, mas busca compreender as biografias, procurando interpretar o modo como os sujeitos posicionam-se na construção do futuro, suas ações e reações diante do vivido, principalmente com referência à sua realização pessoal. Nesse sentido, o projeto aponta para a construção da identidade do jovem que procura compreender: quem ele é? O que deseja para seu futuro?

Nesse processo permeado de descobertas, emoçôes, ambivalências e conflitos, o jovem se defronta com perguntas como: "Quem sou eu?" "Para onde vou?" "Qual rumo devo dar à minha vida?” São questóes cruciais que remetem ao projeto de vida, uma dimensão decisiva no seu processo de amadurecimento (Dayrell, 2011, p. 1).

Para Dias (2009), o projeto de vida é um movimento do sujeito em prol do seu futuro, transformação constante do sujeito, estabelecendo metas e objetivos. $\mathrm{O}$ jovem se projeta no futuro e procura ações no presente que facilitem a sua entrada no mundo adulto, o que a autora chama de "antecipação de uma trajetória" (p. 91). É a partir das informações, vivências e suas experiências sociais que o jovem vai poder construir um rumo para sua vida.

Leão, Dayrell e Reis (2011), com base em Schutz, definem projeto de vida como uma escolha do indivíduo entre as possibilidades (profissionalização, trabalho, escolarização) que tem dentro do contexto socioeconômico e cultural, transformando os desejos e as fantasias em objetivos a serem alcançados; seria dar um rumo à vida. Os projetos apresentam uma dinâmica própria e vão se moldando a partir das mudanças no campo de possibilidades, como a definição utilizada por Alves (2013, p. 161):

Assim, o campo de possibilidades pode ser identificado como sendo as condiçōes estruturais e conjunturais, balizadas pelos limites de ordem social, histórica, econômica, cultural, territorial e pessoal aos quais os projetos estão sujeitos. Não é determinista e também tem certo dinamismo.

Não significa que, por existir o campo de possibilidades, os projetos serão concretizados, pois precisamos considerar a interação entre as dimensões objetivas e subjetivas. Pode acontecer de se terem as possibilidades e não o desejo, ou ter a vontade, mas faltar alguma condição para efetivar o projeto. Dessa forma, mesmo no campo de possibilidades, existem limites e barreiras, às vezes intransponíveis. 
A partir do que discutimos, compreendemos que os projetos nascem no presente, mas implicam uma relação com passado e futuro, diz de um plano que o indivíduo estabelece para alguma área de sua vida (escolar, profissional ou afetiva) e propóe-se a realizar; é viver o presente em prol do futuro. Assim, o projeto precisa considerar a dimensão temporal, que se encontra diretamente articulada na relação do homem com o mundo.

Para Nobre (2010, p. 17), "Somos seres históricos e o tempo é substância de demarcação em nossas vidas. Com ele guardamos uma relação absolutamente particular.". Por isso, a importância, como reconhece Boutinet (2002), de se analisar e questionar o lugar do projeto na vida individual e social à luz da forma como os indivíduos e os coletivos se relacionam com o tempo. Faremos, então, uma leitura histórica, considerando o Período Moderno e a Contemporaneidade, ou a Modernidade e a Pós-Modernidade, apontando a relação do homem com o tempo e como esta influencia na construção dos projetos de vida dos jovens.

\section{A concepção de tempo nos projetos de vida}

A relação entre passado, presente e futuro vem modificando-se ao longo da história humana. Conforme pontua Leccardi (2005), a concepção de futuro como uma dimensão autônoma é algo recente e está associada às ideias hegemônicas do capitalismo. Segundo a autora, o modo de conceber e vivenciar a dimensão temporal muda com as gerações e expressa a dimensão social das diferentes sociedades do processo de civilização. Consequentemente, o modo de compreender e relacionar passado, presente e futuro apresenta-se variável, deslocando-se da concretude do presente para uma dimensão abstrata, imaginária, que retrata o futuro.

A Modernidade emergiu no fim do século XVII, impulsionada pela força da Renascença, que deu aos europeus uma nova confiança em suas capacidades de ultrapassar os antigos. Os pensadores modernos (iluministas) se viram capazes de ir além dos predecessores, superando a ideia dos antigos de que o ensinamento se dava pela experiência, buscando na razão as respostas aos problemas dos homens. Os modernos criaram novos padrōes críticos que originaram a revolução científica, afirmando a importância do progresso (Kumar, 2006).

O tempo moderno caracteriza-se pelas grandes mudanças no modo de vida, nos costumes e organização social, que rapidamente espalham-se no mundo ocidental. $\mathrm{O}$ novo período abre-se a possibilidades, permitindo a mobilidade social; rompe com o passado, hipervalorizando o novo. 
O surgimento da época moderna caracteriza outra relação com o tempo. De acordo com Melucci (2004, p. 19), "Esta surge no horizonte histórico como herança judaico-cristâ". A imagem cíclica do tempo é mantida pelo cristianismo, mas há o acréscimo da noção de gênese e de fim, marcando um percurso linear. Assim, ao afirmar a vinda de Cristo como um fenômeno único e irrevogável, marca-se na história o espaço do novo. A relação com o tempo é alterada para a noção de algo linear, opondo-se à concepção de tempo como cíclico, voltando o olhar do homem para o futuro; o tempo agora é como uma flecha, tem uma finalidade e um fim. Apesar de ser a ideologia cristã a grande precursora da ideia do novo, a noção de tempo com término, reforçada por ela, logo é exorcizada, e o tempo passa a ser vivido como um processo, uma sequência, um antes e um depois sem a ideia de fim.

A concepção cristã de tempo foi secularizada, as divisões em Idade Antiga e Medieval foram elevadas à categoria de estágio, e a História adquiriu um conceito mais dinâmico. O tempo agora seria aberto, moldável pela ação do homem, como nos afirma Kumar (2006, p. 118):

[...] modernidade significava rompimento completo com o passado, um novo começo baseado em princípios radicalmente novos. E significava também o ingresso em um tempo futuro expandido de forma infinita, um tempo para progressos sem precedentes na evolução da humanidade. Nostrumaevum, nossa era, transformou-se em nova aetas, a nova era.

O homem moderno construiu não apenas uma nova relação com o tempo, com vista apenas para o presente e futuro, mas, conforme Kumar (2006), um novo modo de vida. Com características de valorização da ciência e da razão, a Modernidade proclamou que o futuro apontava para o progresso, idealizada pelo avanço no processo de industrialização.

Nesse período, a industrialização alastrou-se impulsionada pela revolução científica do século XVII e, por meio de suas técnicas, fortaleceu a produção industrial no Período Moderno, possibilitando a sociedades ocidentais, em partes pobres e agrárias, a transformação em polos de poder. "A mensagem era simples: em nossos tempos, tempos modernos, só há uma maneira de sobreviver: industrializar-se" (Kumar, 2006, p. 122). Abriu-se, assim, a uma acelerada produção de bens materiais, da qual ainda sofremos as consequências.

Todavia o impacto dessas mudanças foi além da nova organização social; refletiu em todos os aspectos da vida. Repercutiu no modo de vida e nos padróes de subjetividade, o homem agora seria concebido como um ser indivisível e único, o 
que abriu as portas para a individualidade. Dessa forma, a Modernidade libertou o homem de seus apoios estáveis na tradição e estruturas, que anteriormente eram divinamente estabelecidas e, por isso, impossíveis de serem mudadas (Hall, 2005). O homem era visto como sujeito de ação, que podia modificar seu futuro e sua condição no mundo, tinha uma nova identidade temporal com a possibilidade de projetar, tornando o futuro influenciável e permitindo um novo organizador da biografia (identidade).

Nesse sentido, o sujeito, durante o Período Moderno, movia-se na perspectiva de controlar seu plano de vida pessoal e profissional, suas ações diante da vida diziam de métodos para alcançar seus objetivos e metas predeterminados, uma vez que se encontrava diante de um cenário previsível e com garantias. Para o Tempo Moderno, a ação do planejamento exercia papel central para a relação que o sujeito estabelecia com o devir.

Valorizava-se a noção de futuro, e o passado adquiria valor de modo retrospectivo, contribuindo apenas com as realizações planejadas para o futuro. Pautado nessa lógica, o padrão industrial estabelecia etapas de vida bem definidas: as pessoas viviam com um modelo previsível e linear, que prescrevia um roteiro para a vida: aprendizagem, escolaridade, vida profissional, casamento, filhos e aposentadoria. Naturalizavam a perspectiva do futuro por meio de uma determinada sequência. Kholi, citada por Korman Dib (2007), coaduna essa ideia ao afirmar que, na Modernidade, o indivíduo tinha uma trajetória de vida organizada, denominada "biografia normal". A vida profissional era dividida em três estágios bem definidos: uma fase de preparação para o trabalho, uma de atividade econômica e outra de aposentadoria.

$\mathrm{Na}$ Modernidade, o presente era tempo de preparação para o futuro, como espaço de construção do projeto de vida e da própria biografia do jovem. Ambos, projeto e biografia, iriam se estruturar numa relação de correspondência. Nessa lógica, a entrada do jovem no mundo social ficava à mercê de sua ação e a ele cabia construir o projeto de vida e executá-lo, tomando para si a responsabilidade da posição que ocuparia enquanto adulto. É diante dos conhecimentos e informações disponíveis que o indivíduo podia prever, de forma razoável, sobre o futuro, traçando metas e definindo ações para alcançar seus objetivos, como pontua Dib (2007). Dessa forma, a ideia de projeto, plano teve sua origem na Modernidade, persistindo ainda hoje na tentativa de controle do tempo.

É nessa perspectiva que Leccardi (2005, p. 35) usa o termo "diferimento das recompensas", que se caracteriza pela capacidade do sujeito de reprimir os impulsos hedonísticos, adiando para um tempo vindouro a satisfação que se poderia ter no presente, em troca dos benefícios que esse adiamento pode 
trazer no futuro; esse comportamento estava na base dos processos modernos de socialização, nos quais o tempo presente era investido e utilizado de forma racional. Podemos considerar como um exemplo o jovem que deixa de ir a uma festa hoje para estudar e garantir a aprovação escolar no fim do ano. Essa atitude vai ao encontro do pensamento moderno, que espera essa resposta dos jovens, por considerar que estes se encontram na transição para a vida adulta, conforme pontua Leccardi $(2005$, p. 35):

Se considerarmos a fase juvenil como uma fase biográfica de "preparação" para a vida adulta, o diferimento das recompensas aparece como a chave mestra para garantir o sucesso dessa última. Nessa perspectiva, com efeito, é em virtude da capacidade de viver o presente em função do futuro - e, portanto, sacrificar os aspectos "expressivos" das açôes em favor daqueles instrumentais - que o processo de transição pode alcançar um resultado positivo. Aqui, o presente não é apenas uma ponte entre o passado e o futuro, mas a dimensão que "prepara" o futuro.

Esse recurso garantiu para muitos a determinação de um plano de vida, e acreditamos que ainda é utilizado como uma possibilidade de se definir algo para o futuro. Assim, o futuro é considerado a dimensão que agrega o sentido do agir, sendo o espaço da construção dos projetos de vida e definição de si para o jovem, quando este planeja/arquiteta o que fará futuramente. $\mathrm{O}$ diferimento das recompensas implica a noção de um horizonte temporal estendido, exigindo autocontrole, de modo que a programação do tempo é crucial, impondo uma determinada forma de conduzir a vida.

Pensamos que os jovens na Pós-Modernidade podem estar utilizando o diferimento de recompensas a fim de traçar um caminho para o futuro, ou pelo menos tentando, diante do cenário imprevisível que vivem. Desse modo, cabe uma reflexão: mesmo sabendo que, na Pós-Modernidade, temos outra relação com o tempo e com as relações sociais, como veremos a seguir, será que os jovens apresentam hoje esse comportamento? E, se utilizam tal mecanismo, o que os faz pensar que o adiamento das recompensas fará diferença ante um futuro incerto?

De acordo com Castell (como citado em Dib \& Castro, 2010), no Tempo Moderno, o indivíduo se imputava uma autodisciplina no trabalho, suportando as adversidades, na expectativa da recompensa que viria ao final da etapa, fosse ela uma promoção ou uma aposentadoria. O futuro, nesse sentido, vinha naturalmente como etapa conseguinte ao presente, como retorno certo ao investimento realizado durante toda a vida; o presente cumpria função instrumental, operatória, sendo seu tempo destinado a algo no futuro, as 
satisfaçôes imediatas eram renunciadas em nome dos benefícios do futuro. É nessa concepção que se situa a noção moderna de projeto de vida, conforme afirmam Leão, Dayrell e Reis (2011). O futuro se apresenta como dimensão autônoma, sob a influência da subjetividade e da possibilidade de ser controlado pelas forças intelectuais. Essa relação com o tempo modifica-se na Pós-Modernidade, como discutiremos a seguir.

\section{Os projetos na Pós-Modernidade}

O mundo moderno manteve-se firme e confiante em suas ferramentas até meados do século $\mathrm{XX}$, quando foi submetido a rigoroso exame crítico, sendo abalado por suas próprias armas, a razão e a revolução. Esse novo período de transformações tem sido objeto de investigação de diversas áreas de pesquisa, que buscam apresentar uma leitura desse tempo. Por isso é nomeado de diferentes formas pelos estudiosos, o que origina divergências nas nomenclaturas. Tais distinções referem-se ao ponto de abordagem do teórico. Nesse sentido, temos estudiosos que apontam como foco principal os fatores econômicos, outros consideram os avanços da revolução tecnológica, há ainda os que acreditam que vivemos uma nova era, enquanto um outro grupo pontua o momento apenas como uma continuação da etapa anterior. Vários são os nomes utilizados para denominar este período: Revolução das Tecnologias da Informação (Castells, 2000), Pós-Modernismo ou Pós-Modernidade (Bauman, 1998, 2001, Lyotard, 1979), Modernidade Líquida (Bauman, 2001) ou, ainda, Capitalismo Tardio (Jameson, 1991).

Neste trabalho utilizamos Pós-Modernidade (apesar de sabermos que o termo não é uma unanimidade e traz uma série de discussões), pois nosso interesse é marcar a diferenciação com relação ao Tempo Moderno, esclarecendo que vivemos uma etapa que tem sua origem nas mudanças advindas com a Modernidade. $\mathrm{O}$ que consideramos mais relevante é a alteração na forma de perceber e vivenciar este novo período, marcado pelas transformações tecnológicas e pelas incertezas.

Neste período, um conjunto de profundas transformações sociais, econômicas, políticas e tecnológicas coloca em xeque o modelo temporal linear e previsível, proposto pela Modernidade, em que passado, presente e futuro encadeiam-se como etapas da vida de uma biografia normal. De acordo com Leccardi (2005), no final da Segunda Guerra Mundial, a visão de futuro aberto se ampliou acompanhada da noção de liberdade e de incerteza, o que denomina de "crise do futuro", que expressa com clareza o mal-estar vivido na época. Não se tem mais as tradições como referência, tampouco se pode prever o futuro como anteriormente. 
Desse modo, se, na Época Moderna, tínhamos a impressão de vivermos em um mundo estável, agora, neste novo período, tudo se esvai. A Pós-Modernidade tem em sua origem o questionamento do Período Moderno, que colocou a ciência como salvação para todos os problemas da humanidade, mas, diante dos cenários tão devastadores, como as duas guerras do início do século $\mathrm{XX}$, a ideia do Período Moderno entrou em declínio. Iniciou-se por movimentos que questionavam a ideia de novo e de futuro melhor, propagada pela Modernidade.

Nesta nova etapa, encontra-se em evidência a globalização, as comunicações eletrônicas, a flexibilidade e a facilidade na mobilidade. As barreiras e fronteiras são quebradas, novas organizaçōes aparecem devido aos movimentos de fusões, há a descentralização e extraterritorialidade do poder, enfatiza-se o consumismo, e a imprevisibilidade é uma constante, juntamente com o sentimento de imediatismo (Nicolaci-da-Costa, 2004).

As relações apresentam-se marcadas pelo individualismo e a efemeridade, o que instaura uma crise ética sem precedentes, fragilizando o laço social e colocando todos em constante estado de expectativa sobre o momento seguinte. A Pós-Modernidade se apresenta como um período de intensa globalização, e por isso é definida como era de riscos globais, em que se presenciam as ameaças econômicas, terrorismos, maior desigualdade social. Há cada vez menos espaço para as noções de certeza, segurança e controle.

O futuro agora é marcado por um sentimento de alerta e sensação de impotência, acentuando a distância entre as açôes e seus efeitos, que anteriormente apresentavam correlação direta. A Pós-Modernidade traz consigo o estranhamento do futuro e o eminente risco, resultado da perda da relação entre o propósito e a finalidade. Neste momento, os riscos não se referem apenas a uma questão de cálculo, pois não se trata de riscos possíveis de serem governáveis, pois têm um alcance mundial e de difícil prevenção. $\mathrm{O}$ aquecimento global e o terrorismo internacional são exemplos. Nos termos de Leccardi (2005, p. 43), o futuro agora se apresenta "[...] indeterminado e indeterminável, governado pelo risco [...] o futuro foge do nosso controle, com repercussões profundas no plano político e social". Os riscos na Pós-Modernidade têm a atenção concentrada sobre os males que podem surgir no futuro. Dessa forma, a ideia de futuro disseminada é marcada pelo sentimento de alarme e de impotência.

Para Castel, (como citado em Dib \& Castro (2010), a situação de crise experimentada hoje, diante da imprevisibilidade na sequência de vida, gera o desencadeamento dos ciclos de vida. Isso ocorre devido às profundas transformações culturais que perturbam a organização social do tempo e flexibiliza os papéis familiares e as regras sociais, que ordenam os processos de 
integração dos indivíduos, afetando sobremaneira os processos de socialização da juventude.

De acordo com Melucci (1997), o grupo social mais exposto a essas mudanças é a juventude devido às condições culturais e biológicas que vivenciam. A incerteza própria da idade é multiplicada pelos outros tipos de incerteza derivados da nova realidade que apresenta uma ampliação de perspectivas, o que interfere, de forma direta, na produção social dos jovens e nas suas relações com o tempo ante as aceleradas mudanças, à globalização, aos avanços tecnológicos, ao individualismo e à ampliação das incertezas e riscos.

As incertezas do passado estavam ligadas a eventos aleatórios e incontroláveis, pois, muitas vezes, a posição de cada um na vida já estava determinada pelo nascimento, histórico familiar e posição social. Atualmente, as biografias tornaram-se menos previsíveis e os projetos de vida dizem cada vez mais de escolhas do sujeito em seu contexto sociocultural, sendo, por isso, muitas vezes, consideradas responsabilidades dos sujeitos (Melucci, 1997).

É diante dessa fluidez da Pós-Modernidade, na qual nada é determinado ou mesmo definido, que o jovem se vê no processo de entrada na vida adulta. O cenário pós-moderno impossibilita planos de longo prazo ou mesmo a determinação de situações no futuro, de forma que o sujeito só tem o presente como definição. O fato expõe os jovens a uma situação intrigante: como planejar diante de um futuro tão indefinido? Sabe-se que a juventude é o período de preparação para a vida adulta, mas que ações cabem ao jovem para projetar-se no futuro diante deste tempo de incerteza?

São essas transformações no modo de vida que desencadearam a crise existente hoje, na qual a substituição da sequência linear por uma desconexão das etapas vivenciadas pelo sujeito perturbou a organização social do tempo. Pais (2006) relata uma metáfora que ilustra as transformaçóes ocorridas relativas à transição vivida pelos jovens por causa da entrada na vida adulta. Logo após a Guerra na Europa, a transição para a vida adulta aproximava-se de viagens de trens, assim os destinos eram predeterminados, considerando gênero, classe social e formação acadêmica. Nesse contexto, poucas eram as possibilidades de mudar o destino, ou seja, as paradas eram definidas de acordo com um roteiro prévio. Mas, num próximo momento, estas assemelhavam-se a viagens de automóveis, uma vez que o motorista podia controlar seu trajeto diante de suas experiências e percepção, podendo, desse modo, definir roteiros, paradas e desvios.

Todavia, na Pós-Modernidade, o que presenciamos é que não mais as decisões do condutor asseguram a permanência em um caminho ou roteiro preestabelecido, o espaço das transições se apresenta cada vez mais de natureza 
labiríntica (Pais, 2006). Por isso a comparação do labirinto rodoviário ao da vida, pois há sempre interdições, sentidos proibidos, desvios e fatos imprevisíveis que, por vezes, podem obrigar-nos a mudar de caminhos ou mesmo abrir-se a novas escolhas, acentuando, dessa forma, a sensação de desorientação e desordem.

Essa metáfora nos faz refletir que, talvez por perceber o cenário complexo com relação principalmente ao mercado de trabalho, os jovens se preocupem com a formação profissional em um tempo anterior ao que acontecia no Período Moderno. Pais (2006) vai além da metáfora acima e utiliza-se de outra, a do ioiô, para ilustrar o comportamento expresso pelos jovens diante da inconstância nas estruturas sociais:

Perante estruturas sociais cada vez mais fluidas, os jovens sentem sua vida marcada por crescentes inconstâncias, flutuaçóes, descontinuidades, reversibilidades, movimentos autênticos de vaivém: saem da casa dos pais para um dia voltarem; abandonam os estudos para os retornar tempos depois; encontram um emprego e em qualquer momento se veem sem ele; suas paixões são como "voos de borboleta", sem pouso certo; casam-se, não é certo que seja para a vida toda... São esses movimentos oscilatórios e reversíveis que o recurso à metáfora do ioiô ajuda a expressar. (p. 8)

Desse modo, é diante de tantas transformações que o jovem se vê na transição para a vida adulta, sabendo que não se pode ter uma previsão quanto ao amanhã. O sentimento que o invade é de incerteza, repercutindo no seu modo de vida e na perspectiva que tem sobre o futuro. Dayrell e Corrochano (2009) veem a transição para a vida adulta dos jovens como a metáfora do labirinto apresentada por Pais (2006). Por tratar-se de múltiplas trajetórias nas quais os jovens são levados a constantes articulações com a realidade, com as obrigações e com o próprio desejo, vivem encruzilhadas onde atiram a vida e o futuro, procuram construir projetos de vida ou apenas trilhas que possam auxiliá-los na entrada do mundo adulto.

Nesse sentido, o presente é a dimensão do tempo em que o jovem contemporâneo vive sem maiores incômodos, dimensão que inclui e substitui o futuro e permite-lhe fazer escolhas. Leccardi (2005, p. 45) utiliza-se da expressão "presente estendido", definida como "o espaço temporal que bordeja o presente, adquirindo um valor crescente, paralelamente à aceleração temporal contemporânea, favorecida pela velocidade dos tempos tecnológicos e pela exigência de flexibilidade que é seu corolário". É esse presente, um pouco mais ou menos estendido, que possibilitará a definição de escolhas, uma vez que o futuro se torna inviável. 
Assim, agora não mais no futuro, mas no presente mais próximo, é que se pode alcançar o domínio humano e social, projetando-se um pouco à frente no tempo. O presente estendido apresenta-se como área de governo potencial do tempo social e individual, diante do imediatismo e das mudanças aceleradas. Considerando o conceito de presente estendido, podemos compreender que o jovem faz uma escolha de algo que está mais próximo, ou seja, projeta a curto prazo, esperando colher resultados mais pontuais diante da inconsistência vivida.

É neste sentido que Leão, Dayrell e Reis (2011), ao utilizarem a metáfora apresentada por Lévi-Strauss do bricoleur, apontam que não há um plano definido, a criação acontece dentro das possibilidades. O bricoleur é demarcado por um trabalho feito manualmente, no qual se utiliza do material que lhe é disponível e substitui os materiais faltosos pelos que possui, construindo a partir do que se tem em mãos. "Sem ter um projeto muito claro no início, ele vai sendo construído ao sabor do momento, lançando mão de peças disponíveis e que não têm nenhum emprego predeterminado" (Leão, Dayrell \& Reis, 2011, p. 1079).

Ao falar da ampliação de perspectivas, entendemos, como Leão, Dayrell e Reis (2011), que, por estarem envolvidos em uma pluralidade de pertencimentos (grupos de referência, condiçôes sociais, redes associativas), os jovens têm uma multiplicidade de mundos, sejam reais ou imaginários, que, diante da afirmação da incerteza, exigem a decisão da escolha. Os jovens, por sua vez, são chamados a escolher, mas, diante de tantas possibilidades, o que escolher? Melucci (2004) denomina a situação de "paradoxo da escolha", pois, de um lado, a escolha aparece como garantia da individualidade, mas, por outro, remete à exigência de ter de escolher. Sabemos que existem aqueles que não escolhem, seja por questôes de dogmas ou diante da realidade social, mas o que o autor aponta é a recorrência de se escolher sempre, desde ações pequenas do cotidiano a situações bem complexas, e ambos os casos requerem exercícios para a tomada de decisão. Tudo isso vai apontando para a complexidade da situação, trazendo, muitas vezes, uma grande dificuldade na realização de projetos pelos jovens.

\section{Considerações finais}

É diante desse cenário de mudanças, marcado pelas incertezas e pelo risco, que nos encontramos na Pós-Modernidade. As indefinições se apresentam para todos, mas podemos dizer que ela fica potencializada para os jovens, já que o período de transição para a vida adulta não se apresenta definido como em outros tempos. O percurso para a vida adulta agora é imprevisível e cabe a cada um construir e reconstruir sua trajetória. 
A trajetória da juventude para a vida adulta não acontece mais de forma linear como no Período Moderno, não podendo ser definida pela idade cronológica ou tempo de escolarização; a transição evidencia-se de forma complexa e individualizada, apresentando diferentes percursos. Segundo Guerreiro e Abrantes (2005), os jovens hoje alcançam a condição adulta a partir de percursos escolares mais prolongados e inserções profissionais mais tardias e instáveis num mercado de trabalho bastante exigente e competitivo.

Diante do cenário contemporâneo, o sujeito precisa criar planos de curto prazo e desenvolver estratégias para enfrentar essa realidade, que muda rapidamente, assim como elaborar respostas para conseguir saídas diante desse futuro imprevisível. O presente um pouco mais ou menos alargado surge como possibilidade para a definição de escolhas.

Tais considerações nos fazem pensar que o projeto de vida tem se transformado diante do contexto vivido. $\mathrm{O}$ que se observa são tentativas de os jovens se orientarem em uma perspectiva futura, mas com ações focadas no presente, e por isso procuram agir rapidamente, ser velozes, aproveitar o momento e conduzir experimentações que possam influenciar positivamente no seu tempo de vida. Muitas vezes os objetivos alcançados não apresentam o desenho do plano inicial, mas é a partir do que atingem que surgem novas possibilidades para uma vida futura. Assim, investigar a construção dos projetos de vida e os sentidos dados a estes pelos jovens é identificar similaridades, igualdades, na medida em se encontram em uma mesma cultura e tempo histórico, sem ignorar as singularidades, a diversidade e o pluralismo cultural em que vivem. 


\section{Referências}

Alves, M. Z. (2013). Ser alguém na vida. Condição juvenil e projetos de vida de jovens moradores de um município rural da microrregião de Governador Valadares$M G$. (Tese de doutorado). Universidade Federal de Minas Gerais, Programa de Pós-Graduação em Educação, Belo Horizonte.

Bauman, Z. (1998). O mal-estar da pós-modernidade. Rio de Janeiro: Jorge Zahar.

Bauman, Z. (2001). Modernidade líquida. Rio de Janeiro: Jorge Zahar.

Boutinet, J. (2002). Antropologia do projeto. Porto Alegre: Artmed.

Castells, M. (2000). A Sociedade em rede. São Paulo: Paz e Terra.

Dayrell, J. (2011). Por uma pedagogia da juventude. Revista Onda Jovem, 1, 3437. Recuperado a partir de http://www.ondajovem.com.br/acervo/1.

Dayrell, J. \& Corrochano, M. C. (2009). Juventude, socialização e transição para a vida adulta. In M. T. C. Guimarães \& S. M. G. Sousa. Juventude contemporaneidade: desafios e perspectivas. (pp. 119-136). Brasília: Secretaria Especial dos direitos Humanos; Goiânia, Editora UFG, Cânone Editorial.

Dias, M. S. L. (2009). Sentidos do trabalho e sua relação com o projeto de vida de universitários. (Tese de doutorado). Universidade Federal de Santa Catarina, Programa de Pós-Graduação em Psicologia, Centro de Filosofia e ciências Humanas, Florianópolis.

Dib, S. K. (2007). Juventude e projeto profissional: a construção subjetiva do trabalho. (Tese de doutorado). Universidade Federal do Rio de Janeiro, Programa de Pós-Graduação em Psicologia, Rio de Janeiro.

Dib, S. K. \& Castro, L. R. (2010). O trabalho é projeto de vida para os jovens? Cadernos de psicologia social e do trabalho, 13(1), 1-15. Recuperado a partir de http://www.revistas.usp.br/cpst/article/viewFile/25734/27467.

Guerreiro, M. D \& Abrantes, P. (2005). Como tornar-se adulto: processos de transição na modernidade avançada. Revista Brasileira de Ciências Sociais, 20 (58), 157-175.

Hall, Stuart. (2005). Nascimento e morte do sujeito moderno. In: S. Hall. $A$ identidade cultural na pós-modernidade. (10a ed.). (pp. 23-46). Rio de Janeiro: DP\&A. 
Jameson, F. (1991). Pós-modernismo: a lógica cultural do capitalismo tardio. São Paulo: Ática.

Kumar, K. (2006). Da sociedade pós-industrial à pós-moderna: novas teorias sobre o mundo contemporâneo.( 2 a ed. ampl.). Rio de Janeiro: Jorge Zahar.

Leão, G., Dayrell, J. \& Reis, J. B. (2011). Juventude, projetos de vida e ensino médio. Educação e Sociedade, 32(117), 1067-1084.

Leccardi, C. (2005, novembro). Por um novo significado de futuro: mudança social, jovens e tempo. Revista Tempo Social, 17(2), 35-57.

Lyotard, J. F. (1979). A condição pós-moderna. Rio de Janeiro: José Olympio.

Machado, J. N. (2000). Educação: projetos e valores. (2a ed.). São Paulo: Escrituras.

Melucci, A. (1997). Juventude, tempo e movimentos sociais. Revista Brasileira de Educação, 5-6, 5-14.

Melucci, A. (2004). O jogo do eu: a mudança de si em uma sociedade global. São Leopoldo: Editora Unisinos.

Nicolaci-da-Costa, A. M. (2004). A passagem interna da modernidade para a pós-modernidade. Revista Psicologia Ciência e Profissão, 24(1), 82-93.

Nobre, M. R. (2010). Realidade virtual, realidade psíquica na pós-modernidade: um encontro com Freud na infinitude fantasistica do ciberespaço. (Dissertação de mestrado). Pontifícia Universidade Católica de Minas Gerais, Programa de Pós-Graduação em Psicologia, Belo Horizonte.

Pais, J. M. (2006). Buscas de si: expressividade e identidades juvenis. In M. I. M. de Almeida \& F. Eugenio, Culturas jovens: novos mapas de afeto. (pp. 7-21). Rio de Janeiro: Jorge Zahar. 